\title{
The antihypertensive effect of angiotensin-converting enzyme inhibition: $A$ multifaceted mechanism of action
}

THOMAS J. MOORE, M.D.

Boston, Massachusetts

\section{Angiotensin II, a potent} vasoconstrictor, has been implicated as a cause of certain types of hypertension. Drugs that interrupt the reninangiotensin-aldosterone system at several different points have been developed, with the most clinically relevant agents being the converting enzyme inhibitors captopril and enalapril. Captopril, the first of these drugs to become available, seems to enjoy several antihypertensive mechanisms of action. First, it inhibits angiotensin II generation, and most studies would suggest that this is its major mechanism of action.

Additionally, captopril increases bradykinin levels as well as levels of the vasodilator prostaglandin $E_{2}$. Both of these latter factors contribute to the drug's antihypertensive effect. Finally, beyond changing the levels of these hormones in the peripheral circulation, captopril may alter the local generation of each of these substances, contributing further to its antihypertensive action.

The renin-angiotensin-aldosterone (RAA) system has been of extreme interest as a possible cause of or contributor to hypertension. Patients have been categorized as low-, normal-, or high-renin hypertensives, and a variety of drugs have been designed to interrupt or to alter the action of the RAA system. Despite this intense investigation, the renin system has been shown to cause hypertension in only some subsets of patients. ${ }^{1,2}$ Perhaps the most widely accepted subset includes patients with unilateral renal artery stenosis, in whom the resultant hypersecretion of renin leads to high angiotensin levels and angiotensin-dependent hypertension.
The fact that no universal role for renin-angiotensin has emerged in the pathogenesis of hypertension should, perhaps, not be surprising. It is likely that the primary role of the renin axis is not control of blood pressure, but, rather, the control of volume status and protection against salt and water depletion. Sodium depletion increases the secretion of renin and activates the system (Fig. 1). Angiotensin in the kidney reduces renal blood flow and promotes sodium reabsorption; angiotensin also increases aldosterone secretion in the adrenal gland, further enhancing sodium reabsorption in the kidney, and it is known that sodium depletion amplifies aldosterone responsiveness to angiotensin II. Thus, the primary focus of this system appears to be volume regulation, and its effect on blood pressure may not be mediated solely by the vasoconstrictive effects of angiotensin II, but also by changes in volume homeostasis.

\section{Angiotensin II antagonists}

In attempting to lower blood pressure by interrupting the renin-angiotensin axis, several different approaches have been tried. The first of these to become clinically applicable was the development of angiotensin II analogues that act as competitive antagonists of angiotensin at its receptor site. Many such antagonists were developed, but the one most widely used clinically was saralasin. ${ }^{1,2}$ It proved to be a useful tool in identifying angiotensin-mediated hypertension. Our group ${ }^{2}$ found that 86 percent of patients with surgically correctable renal artery stenosis showed a dramatic depressor response during saralasin infusion, indicating that their hypertension was, in part, angiotensin-mediated. The use of saralasin was complicated, however, because the compound was a partial agonist; it inhibited angiotensin when angiotensin levels were high, but mimicked angiotensin when levels were low. Thus, in subjects on a high salt diet (with low circulating angiotensin levels), saralasin 
would sometimes act to increase blood pressure. The utility of this agent was also limited greatly by the fact that it could only be given parenterally. Orally active angiotensin antagonists have not yet been developed.

\section{Angiotensin converting enzyme inhibitors}

Another avenue for blocking the renin-angiotensin system is via inhibition of angiotensin-converting enzyme (ACE), which converts angiotensin I to angiotensin II.

The first such agent to become available for testing in humans was teprotide, a nonapeptide discovered in snake venom. This drug was a very effective antihypertensive in humans, but, because of its peptide nature, it also was limited to parenteral administration.

The first orally active ACE inhibitor was captopril, which was "designed" to custom fit the binding sites of converting enzyme, inhibiting the activity of the enzyme. ${ }^{3}$ Its efficacy as an antihypertensive agent became obvious immediately ${ }^{4}$; its specific mechanism of action has been more difficult to determine.

\section{Inhibition of angiotensin II generation 5,6}

Clearly, captopril inhibits angiotensin II generation. Within 30 to 45 minutes after captopril has been given, angiotensin II levels have fallen and plasma renin levels have increased. This effect is especially evident in sodium-restricted subjects in whom the renin-angiotensin system is already activated. There are several factors, however, that suggest that mechanisms other than angiotensin inhibition contribute to captopril's blood pressure lowering effect. First, the degree of blood pressure fall does not correlate closely with the fall in plasma angiotensin II. Second, captopril lowers blood pressure even in patients with high sodium intake whose renin and angiotensin II levels are very low. Third, as expected, captopril lowers blood pressure in essential hypertensives with high and normal renin levels, but it also significantly lowers blood pressure in patients with low-renin essential hypertension (Fig. 2). ${ }^{4}$ Because these patients have very suppressed renin and angiotensin II levels in plasma, it seems unlikely that captopril exerts its antihypertensive effect solely by angiotensin inhibition.

\section{Bradykinin}

The possible involvement of the kallikrein-kinin system in captopril's mechanism of action was suggested by the fact that kininase II, the enzyme that degrades bradykinin, is identical to ACE. Thus, if a drug blocks angiotensin generation, it might also

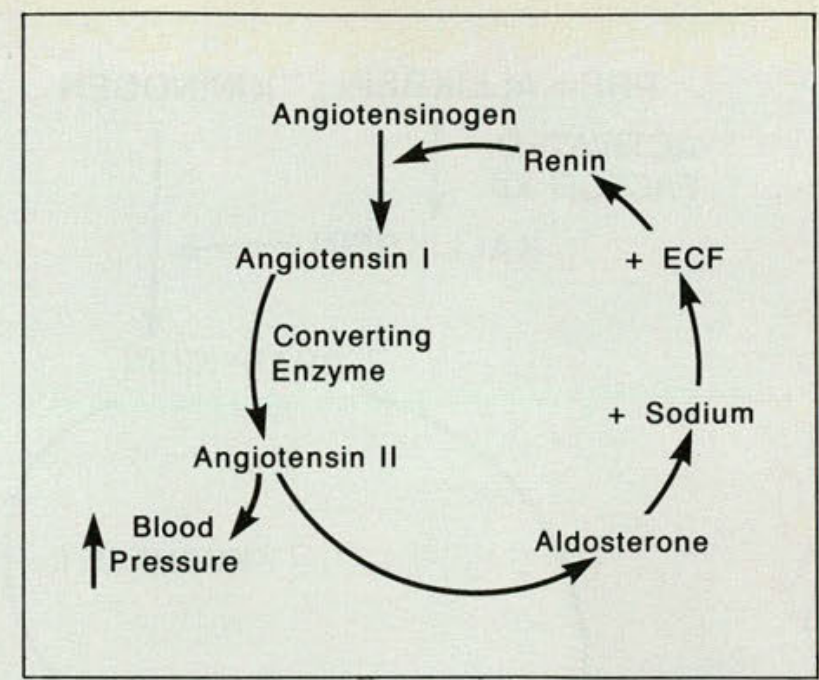

Fig. 1. Feedback loop of the renin-angiotensin-aldosterone system. (ECF = extracellular fluid volume.)

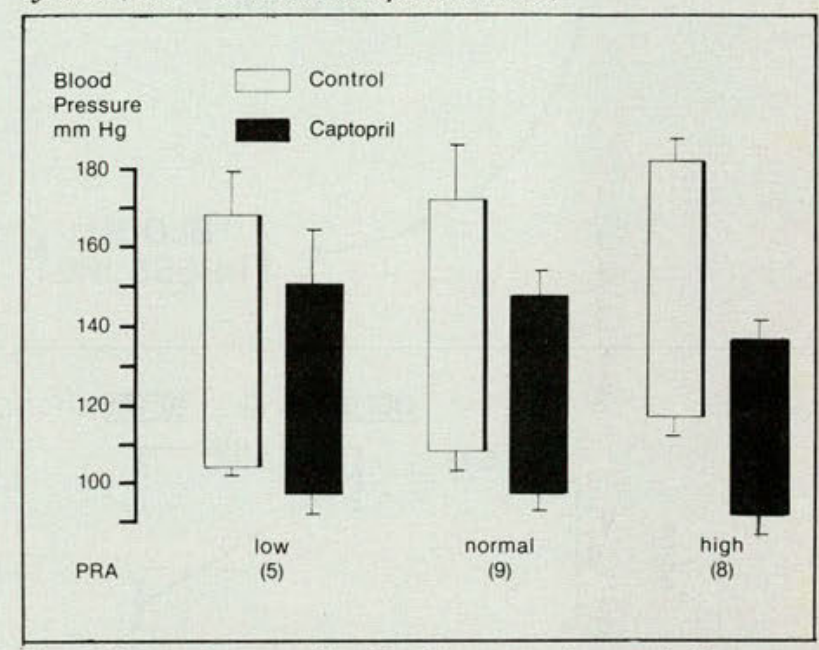

Fig. 2. Effect of captopril on blood pressure in essential hypertensives according to their pretreatment plasma renin levels. (Adapted from Brunner and associates, ${ }^{4}$ with permission.)

block bradykinin degradation (Fig. 3). Because bradykinin is a potent vasodilator, increasing bradykinin levels may also contribute to the antihypertensive effect of captopril. In fact, bradykinin levels have been found to increase after converting enzyme inhibition. ${ }^{7-9}$ Again, however, the antihypertensive response did not correlate with the degree of bradykinin change. In addition, bradykinin administration, while lowering blood pressure, also causes increased cardiac output and heart rate and tends to produce orthostatic hypotension. None of these hemodynamic effects are seen after captopril administration.

\section{Vasodilator prostaglandins}

Another mechanism that has been explored is the possibility that captopril increases the level of va- 

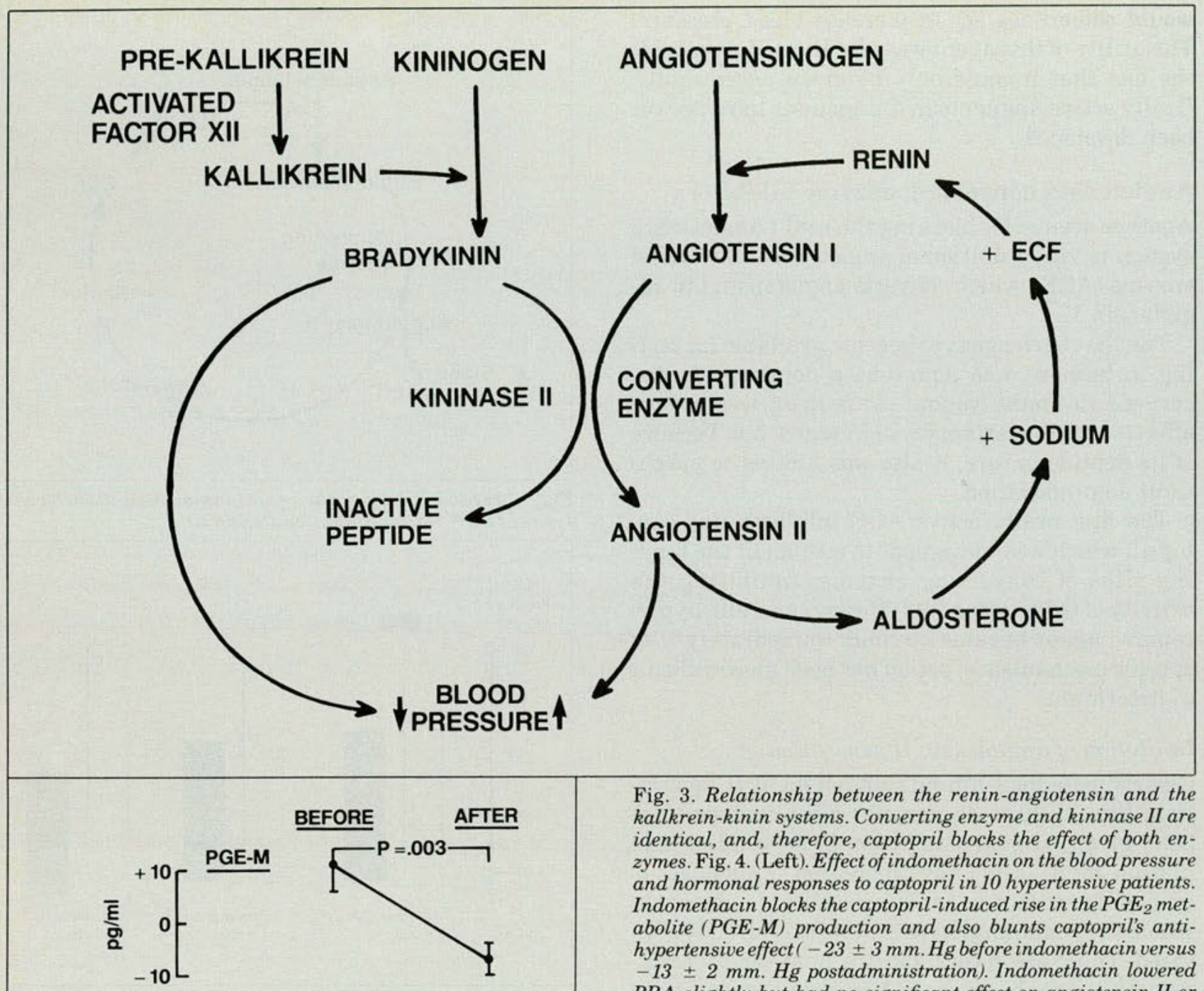

Fig. 3. Relationship between the renin-angiotensin and the kallkrein-kinin systems. Converting enzyme and kininase II are identical, and, therefore, captopril blocks the effect of both enzymes. Fig. 4. (Left). Effect of indomethacin on the blood pressure and hormonal responses to captopril in 10 hypertensive patients. Indomethacin blocks the captopril-induced rise in the $P G E_{2}$ metabolite (PGE-M) production and also blunts captopril's antihypertensive effect $(-23 \pm 3 \mathrm{~mm}$. Hg before indomethacin versus $-13 \pm 2 \mathrm{~mm} . \mathrm{Hg}$ postadministration). Indomethacin lowered PRA slightly but had no significant effect on angiotensin II or kinins. (Adapted from Moore and associates, ${ }^{9}$ with permission.)
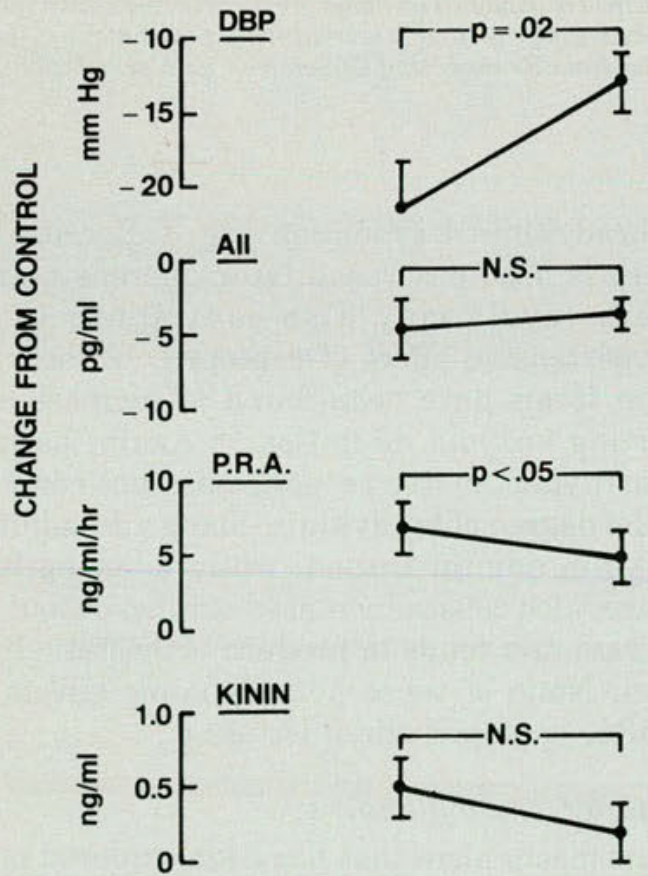

sodilatory prostaglandins. Swartz and associates ${ }^{10}$ and Swartz and Williams ${ }^{11,12}$ found that captopril significantly increases the plasma level of the vasodilator prostaglandin $\mathrm{E}_{2}$. These authors showed that in patients on a high salt diet, in whom angiotensin II and kinin responses to captopril were minimized, the hypotensive response to captopril correlated best with the increases in prostaglandin $\mathrm{E}_{2}$. To further test the importance of these prostaglandin changes, our group ${ }^{9}$ compared the antihypertensive effect of captopril before and after administration of indomethacin, which is a potent inhibitor of prostaglandin synthesis. We found that when prostaglandin $\mathrm{E}_{2}$ changes were blocked by indomethacin, the antihypertensive response to captopril was significantly blunted $(-20 \pm 3 \mathrm{~mm}$. $\mathrm{Hg}$ without indomethacin versus $-13 \pm 2 \mathrm{~mm}$. $\mathrm{Hg}$ after indomethacin administration) (Fig. 4). Cap- 
topril also stimulates the release of prostaglandin $\mathrm{E}_{2}$ from cultured renal medullary interstitial cells, which suggests that this effect of captopril is a direct one. Interestingly, the second ACE inhibitor, enalapril, changes neither bradykinin nor prostaglandin $\mathrm{E}_{2}$ levels. ${ }^{13}$ This finding suggests that the multifaceted mechanism of action may be peculiar to captopril.

\section{Hormonal changes at the tissue level 14,15}

The changes in the circulating levels of all of these hormones provide only an imperfect understanding of captopril's mechanism of action. It is generally agreed that bradykinin and prostaglandins exert their actions locally and that their circulating levels may not accurately reflect local activity. Recent information suggests that the same fact may apply to the renin-angiotensin system. In addition to the kidney, renin has been isolated in blood vessels, brain, adrenal cortex, and even white blood cells. Likewise, angiotensin generation has been reported in many of these tissues. It is possible that captopril may affect local generation of renin-angiotensin in several known angiotensin target tissues (for example, blood vessels and adrenal cortex), and that this local action may actually be more important than the changes in circulating hormonal levels. This intriguing possibility is the subject of intense current investigation.

\section{Summary}

The converting enzyme inhibitor captopril blocks angiotensin II generation. This single mechanism does not, however, account for all of captopril's antihypertensive effects. Captopril also increases kinin levels and production of the vasodilator prostaglan$\operatorname{din} \mathrm{E}_{2}$. These diverse mechanisms explain why captopril lowers blood pressure in a broad range of hypertensives.
1. Hollenberg, N.K., and Williams, G.H.: Angiotensin as a renal, adrenal, and cardiovascular hormone. Response to saralasin in normal man and in essential and secondary hypertension. Kidney Int 15:529-35, 1979

2. Hollenberg, N.K., et al.: Response to saralasin and angiotensin's role in essential and renal hypertension. Medicine 58:115-26, 1979

3. Ondetti, M.A., Rubin, B., and Cushman, D.W.: Design of specific inhibitors of angiotensin-converting enzyme. New class of orally active antihypertensive agents. Science 196:441-4, 22 Apr 77

4. Brunner, H.R., et al.: Oral angiotensin-converting enzyme inhibitor in long-term treatment of hypertensive patients. Ann Int Med 90:19-23, Jan 79

5. Johnston, C.I., et al.: Long-term effects of captopril (SQ14 225) on blood-pressure and hormone levels in essential hypertension. Lancet 1:493-6, 8 Sep 79

6. Millar, J.A., et al.: Acute effects of captopril on blood pressure and circulating hormone levels in salt-replete and depleted normal subjects and essential hypertensive patients. Clin Sci 61:75-83, 1981

7. Swartz, S.L., et al.: Converting enzyme inhibition in essential hypertension. The hypotensive response does not reflect only reduced angiotensin II formation. Hypertension 1:106-11, Mar-Apr 79

8. Swartz, S.L., et al.: Endocrine profile in the long-term phase of converting-enzyme inhibition. Clin Pharmacol Ther 28:499-508, Oct 80

9. Moore, T.J., et al.: Contribution of prostaglandins to the antihypertensive action of captopril in essential hypertension. Hypertension 3:168-73, Mar-Apr 81

10. Swartz, S.L., et al.: Captopril-induced changes in prostaglandin production. Relationship to vascular responses in normal man. J Clin Invest 65:1257-64, Jun 80

11. Swartz, S.L., et al.: Increase in prostaglandins during converting enzyme inhibition. Clin Sci 59:133-55, 1980

12. Swartz, S.L., and Williams, G.H.: Angiotensin-converting enzyme inhibition and prostaglandins. Am J Cardiol 49:1405-9, 21 Apr 82

13. Shoback, D.M., et al.: Time course and effect of sodium intake on vascular and hormonal responses to enalapril (MK 421) in normal subjects. J Cardiovasc Pharmacol 5:1010-8, 1983

14. Vidt, D.G., Bravo, E.L., and Fouad, F.M.: Medical intelligence. Captopril. N Engl J Med 306:214-9, 28 Jan 82

15. Zusman, R.M.: Renin and non-renin-mediated antihypertensive actions of converting enzyme inhibitors. Kidney Int 25:969-83, 1984

Dr. Moore is an assistant professor of medicine, Brigham \& Women's Hospital, Harvard Medical School, Boston, Massachusetts.

Dr. Moore, Endocrine-Hypertension Unit, Brigham \& Women's Hospital, Harvard Medical School, 75 Francis Street, Boston, Massachusetts 02115. 